\title{
Os Ratings de Risco Soberano e os Fundamentos Macroeconômicos dos Países: Um Estudo Utilizando Redes Neurais Artificiais
}

\author{
Bruno Ferreira Frascaroli* \\ Luciano da Costa Silva** \\ Osvaldo Cândido da Silva Filho***
}

\section{Resumo}

Para mitigar as conseqüências da assimetria de informações, os ratings de risco soberano são instrumentos que constituem peça chave para determinar as condições dos mercados de crédito externos, fundamentais para o desenvolvimento de países emergentes como o Brasil. No presente trabalho estudou-se a partir dos fundamentos macroeconômicos, a classificação dos ratings de risco soberano realizadas pelas agências de ratings encontrando uma classificação própria de risco dos diversos países emergentes utilizando Redes Neurais Artificiais. Observou-se o grau de homogeneidade entre as atribuições de ratings e os fundamentos macroeconômicos dos países da amostra, na qual quatro fundamentos mostraram-se mais intimamente ligados às atribuições. Logo após, num exercício de estática comparativa, utilizou-se o modelo para fazer simulações de cenários das condições externas de crédito para o Brasil ao modificar os fundamentos macroeconômicos. Estes cenários indicam que as agências esperam por crescimento mais acentuado do produto per capita e pela diminuição da dívida pública.

Palavras-chave: rating de risco soberano; fundamentos macroeconômicos; redes neurais artificiais.

Códigos JEL: C45; G14; E44.

\section{Abstract}

To minimize the consequences of asymmetric information, the sovereign risk ratings are instruments that constitute a key piece in the determination of credit market conditions, essential to the growth of developing countries like Brazil. In the present work we studied based on macroeconomics foundations, a classification to sovereign risk ratings realized by the ratings agencies finding the classification using Artificial Neural Networks. We observed homogeneity degree between the attributions of agencies and macroeconomics foundations in the countries of sample which four of foundations seem to be more directly

Submetido em Junho de 2008. Aceito em Novembro de 2008. O artigo foi avaliado segundo o processo de duplo anonimato além se de ser avaliado pelo editor. Editor responsável: Ricardo Leal.

*Doutorando em Economia pelo PIMES - UFPE. Tel: (81) 3453-5986.

E-mail: brunoarizona@yahoo.com.br

**Doutor em Matemática Aplicada pelo IME - USP e Professor Dr. do Departamento de Estatística - UFPB. Tel: (83) 3216-7075. E-mail: luciano.prof@gmail.com

***Doutorando em Economia pelo PPGE - UFRGS. Tel: (51) 3224-9371.

E-mail: candido_f@ibest.com.br 
connected with these attributions. After, in a comparative static exercise, we use the model to make simulations of sceneries of the credit external conditions for the Brazilian economy, changing the macroeconomics foundations which we noted that agencies expected for more per capita income increasing and decrease of public debt.

Keywords: sovereign risk rating; macroeconomics foundations; artificial neural networks.

\section{Introdução}

Transações financeiras são inexoravelmente caracterizadas por assimetrias de informação entre fornecedores e tomadores de recursos. Os últimos têm necessariamente conhecimento mais amplo sobre sua própria capacidade de pagamento tanto a respeito da disposição de recursos e prazo de pagamento do que aqueles que lhes fornecem recursos. Portanto, do ponto de vista dos fornecedores de recursos, a presença de tal assimetria afetará os prêmios pelos riscos de crédito exigidos em qualquer operação de crédito e aquisição de títulos financeiros (Canuto e Santos, 2003).

Nos estudos sobre determinantes de crescimento e desenvolvimento econômico das nações é de suma importância estudar-se o mercado financeiro destas. O objeto de estudo do presente trabalho foi estudar a classificação dos ratings de risco soberano realizadas pelas agências de rating e seu propósito foi, a partir dos fundamentos macroeconômicos das diversas nações, classificar os riscos soberanos dos diversos países emergentes utilizando o critério de risco estimado por Redes Neurais Artificiais.

Tomando a classificação estimada, estudou-se a homogeneidade entre as atribuições das agências e os fundamentos macroeconômicos dos países da amostra. Esta classificação se baseou na localização de elementos constituintes e classificação a posteriori das mudanças de estado dos movimentos das séries temporais macroeconômicas determinantes das atribuições dos ratings de risco soberano desses países e das séries de risco soberano fornecidas pelas agências de rating. Logo após, utilizou-se redes neurais artificiais para fazer simulações de cenários das condições externas de crédito para a economia brasileira a partir de mudanças em seus fundamentos macroeconômicos.

Com as simulações de cenários foi possível um exercício de estática comparativa para saber quais variáveis estão mais correlacionadas com o fenômeno dos ratings e se as direções destas correlações estão em acordo com a teoria econômica contemporânea que contemplam aspectos microeconômicos dos contratos sob informações assimétricas.

Os resultados indicam que as agências de ratings esperam por crescimento mais acentuado do produto per capita e pela diminuição da dívida pública. Desta maneira, a informação gerada ao aplicar com devida parcimônia o modelo de redes neurais pode servir como uma ferramenta objetiva de apoio à decisão.

As redes neurais são aproximadores universais de funções. Elas são bastante similares às regressões lineares e não-lineares pelo método de mínimos quadrados ordinários (MQO), logo as primeiras podem ser vistas como uma abordagem 
estatística alternativa para resolver problemas que envolvem análise recursiva de informações. Ambos os métodos envolvem minimização da soma dos quadrados dos erros de estimação (Kaastra e Boyd, 1996).

Como a economia brasileira necessita de fluxos de capitais externos para equilibrar seu balanço de pagamentos, é possível compreendermos como os fundamentos macroeconômicos e as atribuições de ratings afetam a economia restringindo ou ampliando sua captação de recursos no mercado financeiro internacional. Vale ressaltar que mesmo após a estabilização de algumas variáveis macroeconômicas a partir de 1994, a dificuldade de captação de recursos no mercado financeiro internacional provocou uma mudança na política cambial em janeiro de 1999.

Desta forma, torna-se claro a importância de estudos sobre as condições do mercado de crédito internacional haja vista que países emergentes como o Brasil, não são auto-suficientes em recursos financeiros tornando-se tomadores líquidos de recursos neste mercado. Reinhart (2001) salienta que, justamente para países emergentes tomadores líquidos de recursos, as condições de captação de recursos é mais crítica. Para estes países, as agências de rating possuem um comportamento mais severo, no sentido de, freqüentemente, penalizar estes países com downgrades ${ }^{1}$ mesmo que seus fundamentos macroeconômicos estejam estáveis. O mesmo é válido em Hooper et alii (2008), no qual é observado o impacto das volatilidades de mercado principalmente sobre as economias emergentes na forma de downgrades.

Com base em verificações empíricas anteriores a este trabalho, a análise foi direcionada para a relação entre as atribuições de ratings dos países emergentes e seus respectivos fundamentos macroeconômicos, no sentido de examinar se realmente há uma relação próxima de causalidade entre a primeira e a segunda, aqui assumida como a capacidade dos países saldarem suas obrigações.

Um rating é uma estimativa da probabilidade de haver inadimplência futura. É importante entender que os ratings soberanos abordam o risco de crédito de governos nacionais (Standard \& Poor's, 2004). Ele é um ponto de vista sobre risco relativo baseado na capacidade e vontade do emissor para pagar completamente e no prazo acordado, principal e juros, durante o período de vigência do instrumento de dívida e severidade da perda, em caso de inadimplência (Moody's Investors Service, 2003).

Quanto maior o risco que investidores assumem em adquirir algum título de um governo soberano, menor a capacidade deste governo em tornar atraente esta aquisição e, portanto, atrair capital estrangeiro. Em conseqüência, maior é o prêmio remunerado aos investidores para compensá-los por assumir esse risco. Cantor e Packer (1996) confirmam que existe uma correlação inversa entre as atribuições de ratings realizadas pelas agências e o spread de prêmios pagos entre títulos dos governos soberanos e os títulos do governo norte-americano, isto é, quanto menor o conceito atribuído pela agência (maior risco) maior a remuneração

\footnotetext{
${ }^{1}$ Rebaixamento na posição dos ratings que significa elevação de risco soberano na escala das agências de ratings.
} 
paga pelo título, embora a habilidade dos ratings para explicar spreads relativos não pode ser completamente atribuída à correlação mútua com indicadores de risco soberanos.

Stiglitz e Greenwald (2004) justificam que o mercado de capitais possui características especiais pelo fato de negociar crédito, isto é, o mercado de capitais possui particularidades que o torna diferente dos demais. Segundo eles, existe informação assimétrica neste mercado. Este fenômeno causa problemas de risco moral e seleção adversa. ${ }^{2}$ O risco moral surge pela incapacidade dos fornecedores de crédito, seja operacional ou por elevados custos, de monitorarem as ações dos tomadores de recursos após o contrato de concessão de crédito. A seleção adversa surge da informação assimétrica obtida pelos fornecedores de crédito a respeito dos projetos de investimentos dos tomadores de recursos que serão feitos com recursos emprestados.

Quando é possível diminuir os efeitos maléficos da assimetria de informação no sistema financeiro o volume de transações se desenvolve. Diminuir especialmente problemas advindos do risco moral, entendendo seus mecanismos de ajuste através da modelagem de reputação dos agentes, como apresentado em Obstfeld e Rogoff (1996). Assim, algumas medidas como coleta e processamento de informações antes das operações, firmação de contratos mais claros e monitoramento dos tomadores de recursos de modo a controlar o uso dos recursos após seu fornecimento agem no sentido de desenvolver o sistema financeiro. Entretanto, tais medidas operam com custos que, às vezes, oneram demasiadamente as partes que negociam recursos e nem sempre essas medidas têm eficácia suficiente para suprimir essa assimetria de informação.

Neste sentido, a presença de instrumentos de ordem legal, assim como instrumentos institucionais que sustentem o cumprimento de contratos e o exercício de garantias, a assimetria de informações e os prêmios cobrados como compensação pelos riscos de crédito diminuem.

Em conformidade com Canuto e Santos (2003), um risco em particular é o risco soberano, isto é, o risco de crédito vinculado a operações de crédito concedidas a estados soberanos. Os colaterais e o cumprimento dos contratos são distintos daqueles presentes nos casos de crédito para agentes privados. Adicionalmente, a disponibilidade da capacidade de pagamento é diferente, pois entre seus determinantes estão as variáveis macroeconômicas que indicam as expectativas a cerca da capacidade futura de pagamento daquele país que toma recursos emprestados. Entre estas, podemos destacar as reservas de divisas estrangeiras, crescimento econômico, capacidade de arrecadação tributária, etc.

Em complemento, este trabalho faz uma breve análise acerca dos principais modelos de redes neurais utilizados durante as estimações experimentais. Foram executados os estágios de implementação do modelo, encontrando, treinando através de aprendizagem supervisionada e testando a arquitetura de redes neu-

${ }^{2}$ Para uma discussão mais detalhada sobre risco moral e seleção adversa consulte Mas-Colell et alii (1995) e Arnott e Stiglitz (1988). 
rais para analisar as séries temporais macroeconômicas de um conjunto de países emergentes e, a partir delas, o modelo escolhido pôde aprender como funciona a atribuição de ratings de risco soberano para estes países e, a partir da arquitetura encontrada nos experimentos, foram realizadas simulações sobre as condições de crédito para a economia brasileira a partir de mudanças dos comportamentos dos determinantes macroeconômicos das atribuições de rating.

O presente artigo está organizado de modo que além desta breve introdução, na seção 2 discute-se a problemática envolvendo a questão dos ratings, das agências e dos possíveis impactos dos ratings no lado real da economia. Na terceira seção, aborda-se a metodologia do trabalho, aspectos históricos das redes neurais, detalhando seus principais aspectos técnicos. Logo após, dedica-se a seção 4 para apresentar as variáveis que fazem parte da entrada da rede neural e como estas foram previamente trabalhadas para serem introduzidas no modelo. Na seção 5, apresenta-se resumidamente a implementação de uma rede neural e logo após se analisa os resultados encontrados no trabalho. Finalizando com a seção conclusiva em que se examina a ligação da problemática econômica tratada com os resultados empíricos fornecidos pela rede neural.

\section{Literatura de Ratings de Risco Soberano}

O rating de risco soberano é um indicador que busca expressar o risco ao qual se submetem os investidores estrangeiros ao adquirir títulos de algum país. Os ratings de risco soberano são construídos com base em análises das conjunturas econômica, social e política dos países e, por este motivo, podem ser subjetivos porque envolvem julgamento não só das variáveis macroeconômicas internas e externas no presente, mas também das perspectivas das mesmas para o futuro.

As agências de rating são empresas independentes de qualquer interesse, quer por parte de governos ou de empresas privadas. Essa característica lhes permite ter como princípios: independência, objetividade, credibilidade e liberdade de divulgação de avaliações com relação à qualidade de crédito dos emitentes e emissões de dívida (Standard \& Poor's, 2002). Dentre as principais agências de rating de risco temos, por exemplo, Standard \& Poor's, Moody's Investor Service e Fitch IBCA. ${ }^{3}$

A presença de agências de rating como fornecedoras de mercadoria, neste caso, o processamento de informações, constitui peça-chave para que a oferta de recursos financeiros não fique restrita às instituições financeiras domésticas, permitindo ao governo central destas economias e às empresas domésticas, ampliarem suas possibilidades de tomarem recursos.

${ }^{3}$ Segundo Bone (2005), as agências Standard \& Poor's e Moody's Investor Service detém juntas cerca de $80 \%$ do mercado de classificação de ratings. Este seria então, um mercado de concorrência imperfeita o que implica em diferentes ganhos de escala para captar informações por parte de cada agência individual, exigindo por este lado, uma série de considerações como algumas levantadas por Perrelli e Ramos (1998). 
Os ratings normalmente tentam refletir os fatores específicos de risco de um país, os quais podem trazer conseqüências sobre a capacidade de uma entidade para saldar integral e pontualmente sua dívida. Fazem parte destes fatores de riscos o risco de intervenção soberana, como, por exemplo, o risco de um país impor políticas cambiais ou decretar moratória da dívida. Além disso, inclui os riscos econômico ou país, que se referem ao ambiente econômico, político e social, o qual influencia tanto os ratings do próprio país quanto aquelas entidades emissoras ali presentes, embora hajam empresas brasileiras, por exemplo, como a Petrobrás que romperam este 'teto' ao manter-se como investment grade acima da atribuição soberana (Standard \& Poor's, 2001).

A Tabela 1 traz as escalas das classificações feitas pelas principais agências de rating do mundo, onde temos uma escala numérica crescente de risco que vai de a1 a 24. Países que se encontram na escala de a1 a 10 pertencem ao grupo de países de menor risco chamados de investment grade e países que se encontram na escala acima de 10, fazem parte de países de maior risco, o que configura um comportamento especulativo no mercado financeiro. Países que estão na ordem da escala de a22 a 24 são países que declararam moratória de suas dívidas. Logo, as classificações de obrigações nesta categoria são baseadas na possibilidade de recuperação parcial ou total do empréstimo.

Tabela 1

Sistemas de classificação de ratings

\begin{tabular}{ccccc}
\hline \multirow{2}{*}{ Posição } & \multicolumn{3}{c}{ Empresas } & Escala Numérica \\
\cline { 2 - 4 } & Moody's & S \& P & Fitch & \\
\hline \multirow{5}{*}{ Investment Grade } & Aaa & AAA & AAA & 1 \\
& Aa1 & AA+ & AA+ & 2 \\
& Aa2 & AA & AA & 3 \\
& Aa3 & AA- & AA- & 4 \\
& A1 & A+ & A+ & 5 \\
& A2 & A & A & 6 \\
& A3 & A- & A- & 7 \\
& Baa1 & BBB+ & BBB+ & 8 \\
& Baa2 & BBB & BBB & 9 \\
& Baa3 & BBB- & BBB- & 10 \\
\hline \multirow{5}{*}{ Especulativa } & Ba1 & BB+ & BB+ & 11 \\
& Ba2 & BB & BB & 12 \\
& Ba3 & BB- & BB- & 13 \\
& B1 & B+ & B+ & 14 \\
& B2 & B & B & 15 \\
& B3 & B- & B- & 16 \\
& Caa1 & CCC+ & CCC+ & 17 \\
& Caa2 & CCC & CCC & 18 \\
& Caa3 & CCC- & CCC- & 19 \\
& - & CC & CC & 20 \\
& - & C & C & 21 \\
& Ca & SD & DDD & 22 \\
& C & D & DD & 23 \\
& - & - & D & 24 \\
\hline
\end{tabular}

Fonte: Standard \& Poor's, Fitch Ratings e Moody's. 


\subsection{O papel dos ratings no mercado}

$\mathrm{O}$ rating de risco soberano exerce impacto direto ou indireto sobre a qualidade de crédito das entidades que operam em uma determinada localização de diversas maneiras. Cantor e Packer (1996), ressaltam que os ratings são importantes não apenas porque alguns dos maiores emissores de dívidas são governos soberanos, mas também porque de acordo com as atribuições de ratings, a captação de recursos por governos estaduais, municipais ou empresas privadas localizados nestes países é afetada.

$\mathrm{Na}$ presença de informações assimétricas nos mercados financeiros mundiais, as classificações realizadas pelas agências de rating do risco de crédito são sinalizações para os agentes participantes do mercado financeiro, isto é, nesta análise é considerado o fato dos participantes deste mercado realizar suas decisões por meio da utilização de racionalidade limitada ${ }^{4}$, o que foi devidamente coberto neste estudo em termos de modelagem empírica.

Bone (2004) resume os motivos pelos quais, o mercado sustenta a existência das agências de rating:

- O rating deve possuir idoneidade, isto é, ele vale apenas quando é confiável. Dado que uma agência de rating se financia cobrando o custo de elaboração do rating dos emitentes de dívidas, ela não possui qualquer incentivo de produzir ratings com viés ou não-confiáveis;

- Outro argumento importante do mercado para o rating se deve aos custos de captar e interpretar informações sobre os emitentes de dívidas. Assim, as agências de rating possuem retorno de escala na captação e interpretação dessas informações;

- O rating tem a capacidade de sintetizar as informações sobre a futura qualidade de crédito do emitente de dívidas de uma forma clara e simples para o mercado.

\subsection{Críticas ao papel dos ratings}

Estudos mostram que há um atraso nas mudanças nas atribuições dos ratings por parte das agências frente às mudanças ocorridas nos mercados, e estas se antecipam às mudanças nas atribuições dos ratings (Partnoy, 2002). Um exemplo desse comportamento é descrito em Andritzky et alii (2007) no qual se percebe que os agentes, durante as crises nos mercados financeiros, passam a monitorar as variáveis macroeconômicas no tempo e deixam em segundo plano as informações contidas nos ratings, em outras palavras, semelhante ao que está acontecendo neste momento em relação ao mercado imobiliário americano, os agentes percebem a inabilidade das agências em prever os comportamentos dos mercados e tentam

\footnotetext{
${ }^{4}$ Veja mais sobre racionalidade limitada e demais conceitos relacionados a decisões sob informação assimétrica e incerteza em Rasmusen (2006) e Kreps (1990).
} 
captar mais informações contemporâneas à respeito das economias envolvidas em processos de ajustamento.

Assim, a eficácia do objetivo do rating seria gravemente prejudicada, pois se as agências de rating se propõem a avaliar a condição futura de pagamento de um emitente de dívida, e esta é realizada após a mudança de percepção do mercado, os agentes não mais se apoiariam no rating como uma informação fidedigna de tal condição futura de pagamento de um emitente de dívida.

Além disso, Cantor e Packer (1996) observam que há uma forte convergência das atribuições dos ratings realizados pelas agências Standard \& Poor's e Moody's, de modo que, quando estas agências atribuem ratings diferentes, esta diferença frequentemente é de apenas uma posição na escala de ratings, o que configura uma tendência conservadora destas atribuições.

Segundo Partnoy (2002), existe um paradoxo no mercado financeiro envolvendo os ratings atribuídos pelas agências. Embora haja cada vez menos informações contidas nos ratings atribuídos pelas agências, estas parecem estar em contínua prosperidade. $\mathrm{O}$ autor aponta para a existência de ineficiências de ordem legal existentes nos mercados financeiros que explicam este paradoxo. Numerosas regras legais e regulamentações dependem substancialmente dos ratings e, particularmente, daqueles atribuídos por uma pequena parte das agências de rating que fazem parte da Nationally Recognized Statistical Ratings Organizations (NRSROs). Contudo, as barreiras para entrar no mercado de NRSRO são proibitivas.

Logo, os ratings atribuídos pelas agências de rating que fazem parte da NRSRO são valiosos para os participantes do mercado financeiro mesmo que o conteúdo informacional deles não seja maior que a informação pública neste contida. Agentes que administram recursos de investidores institucionais, por exemplo, estão submetidos às regulamentações internas da administração dos fundos que atribuem o risco existente na construção das carteiras com base nos ratings. Assim, mesmo que os ratings não forneçam uma informação adequada sobre os riscos de determinados emitentes, os administradores desses fundos são obrigados a utilizá-los.

As agências de rating fracassaram em antecipar o declínio rápido nos preços de centenas de papéis financeiros na crise de 1929 e, em conseqüência deste fato, numerosos ratings foram abruptamente baixados, o que pela primeira vez, demonstra uma mudança generalizada na atribuição de ratings pelas agências, tornando-se mais conservadoras (Partnoy, 2002). Neste mesmo trabalho é demonstrado que após 1973, o aumento da utilização dos ratings como instrumento de regulamentação, mudou a natureza do produto vendido pelas agências de rating, pois estes ao invés de fornecerem informação, determinam a conduta dos agentes no mercado financeiro por meios legais.

Mais recentemente, de acordo com Ferri et alii (1999), diversos observadores e instituições do mercado financeiro como, por exemplo, Banco Mundial e Fundo Monetário Internacional (FMI) apontaram para a falha das agências de rating em alertar antecipadamente o mercado sobre a crise asiática de 1997. Parecido com o que houve na crise de 1929, as agências de rating baixaram os ratings de risco 
soberano de alguns países envolvidos na crise configurando novamente um comportamento excessivamente conservador em vista do que os fundamentos macroeconômicos justificariam. Em reconhecimento a esta falha, uma destas agências, a Fitch IBCA, em comentário público em janeiro de 1998, reconhece não ter dado a devida atenção às dívidas de curto prazo em moeda estrangeira destes países. Após a crise asiática, a Moody's, em declaração, também enfatiza a importância das dívidas de curto prazo em moeda estrangeira.

Bone (2002) afirma que antes da crise na Ásia em 1997 as mudanças nos ratings soberanos não eram significativas e se mostravam historicamente estáveis. Após a crise asiática, mais precisamente de julho de 1997 a novembro de 1998, foram observados downgrades abruptos não comparáveis aos que ocorriam anteriormente. Cruces (2006) num estudo sobre as propriedades estatísticas dos ratings de risco soberanos, também compartilha a visão de que após a crise asiática há mudanças nos comportamentos das agências e vai além, no sentido de comparar os efeitos desta crise com o alto grau de endividamento de economias emergentes ocorrido na década de 1980, concluindo que a primeira é mais significativa para a mudança de comportamento na condução das atribuições realizadas pelas agências.

O trabalho de Ferri et alii (1999), postula a existência de uma regra procíclica das agências de rating o que prolongaria os efeitos de crises sobre as economias através de comportamentos excessivamente conservadores dessas agências na medida em que elas baixam excessivamente os ratings de risco soberano de economias que já possuem baixos ratings de risco soberano na escala. Ao passo que, segundo os autores, em economias com rating de risco soberanos mais elevados isso não acontece, pelo contrário, essas economias experimentam atribuições crescentes de rating.

Após as crises, as agências de rating se tornam mais conservadoras porque são pegas de surpresa e têm mais dificuldade de reconstruir suas reputações. Assim, como a reputação dessas agências é prejudicada também o retorno de seus serviços também é prejudicado. Logo, elas são incentivadas a se tornarem mais conservadoras para não falharem novamente. Contudo, os ratings atribuídos pelas agências não devem ser utilizados como um remédio às crises financeiras, mas como uma síntese para formação de expectativas futuras.

\subsection{Determinantes das Atribuições de Ratings}

Os ratings de risco soberano atribuídos pelas agências para as diversas nações do mundo usam critérios que nem sempre são claros, ou seja, não há um padrão de quais são os determinantes para as avaliações destes e nem das ponderações utilizadas para cada determinante, pois estes ratings são compostos de uma combinação de determinantes qualitativos e quantitativos. 
The agencies never describe their terms or analysis precisely or say, for example, that a particular rating has a particular probability of default, and they stress that the ratings are qualitative and judgmental. This secretive, qualitative process is not the type of process one would expect if the agencies had survived based on their ability to accumulate reputational capital. On the other hand, such processes make it more likely that an agency would be able to survive in a non-competitive market; if the rating process had been public or quantitative (rather than qualitative), other market entrants easily could have duplicated the rating agencies technology and methodology (Partnoy, 2002, 12 p.).

Dentre os determinantes qualitativos de atribuição dos ratings temos determinantes de riscos políticos, como, por exemplo, a probidade das lideranças, estabilidade e transparência das instituições, que fazem parte do julgamento dos analistas sobre o comportamento destes governos frente às decisões em momentos de crises econômicas. Haque et alii (1998), confirmaram empiricamente que variáveis políticas não têm nenhum ou quase nenhum impacto sobre a decisão de atribuição de ratings por parte das agências. Uma possível explicação apontada por eles é a de que as variáveis econômicas absorvem instantaneamente flutuações originadas no âmbito político. Diante disso, no presente trabalho utilizamos fundamentos macroeconômicos para buscarmos explicar a decisão de atribuição de ratings pelas agências.

Os determinantes quantitativos incluem diversas medidas de desempenho econômico e financeiro, bem como as obrigações contingenciais, embora o julgamento sobre a integridade da amostra desses dados seja uma questão mais qualitativa. Não há uma fórmula exata para se combinar os escores ao se determinar os ratings. As variáveis analíticas são inter-relacionadas e os pesos não são fixos, nem entre os diversos governos soberanos nem ao longo do tempo (Standard \& Poor's, 2004).

Cantor e Packer (1996), confirmam que, mesmo para os determinantes quantitativos, é difícil encontrar uma relação entre os pesos atribuídos aos determinantes pela Moody's e pela Standard \& Poor's, por causa do grande número de critérios adotados por estas agências.

A empresa Standard \& Poor's divide a estrutura dos determinantes dos ratings soberanos em categorias. Para atribuir ratings de crédito, cada governo soberano é classificado dentro de uma escala - cujas notas vão de um (a mais alta) até seis aplicadas a cada uma das categorias analíticas (Standard \& Poor's, 2004).

Dentre os determinantes, podemos enumerar alguns, na mesma linha de trabalhos como, por exemplo, Cantor e Packer (1996), Canuto et alii (2004), Rowland (2004), que aqui serão utilizados como entradas no processo de aprendizagem supervisionada para criação de um critério de risco soberano. Podemos dividir estes determinantes em variáveis utilizando o mesmo critério de divisão adotado por Rowland (2004), apenas adicionando mais uma categoria de variáveis determinantes do desenvolvimento e estabilidade econômica. 
- Variáveis de Solvência: Taxa de crescimento das exportações de bens e serviços; taxa de crescimento das importações de bens e serviços; e dívida de longo prazo como percentual do produto.

- Variáveis de Liquidez: Nível de reservas totais como percentual do produto; dívida externa total como percentual das exportações de bens e serviços; serviço da dívida total como percentual das exportações de bens e serviços; e balança externa de bens e serviços como percentual do produto.

- Variáveis de desenvolvimento e Estabilidade Econômica: Taxa de crescimento do produto per capita; evolução do nível de preços ao consumidor; e grau de abertura econômica medidas pela soma do volume das exportações mais importações como percentual do produto.

O modelo econométrico de Cantor e Packer (1996) é seminal, no sentido de ajustar um bom modelo de previsão para as atribuições de ratings através da amostra de séries temporais de dados macroeconômicos. Porém, após a crise asiática ocorrida em 1997, o modelo econométrico destes autores não mais consegue uma boa capacidade preditiva das atribuições de ratings. Adicionalmente, eles chamam a atenção para a limitação de modelos quantitativos na incapacidade de explicar todos os movimentos das atribuições dos ratings, haja vista que estes tipos de modelos têm dificuldade de inserir entre suas variáveis explicativas, variáveis qualitativas.

O trabalho de Ferri et alii (1999), chama a atenção para o que seria o modelo utilizado pelas agências na atribuição de ratings após a crise asiática de 1997. Este modelo principal é dividido em dois modelos. Um modelo quantitativo em função dos determinantes de ordem macroeconômica. E um modelo de informações ad hoc de cada país, refletindo o julgamento das agências. O modelo pode ser expresso da seguinte maneira:

$$
\text { Ratings }=\omega_{q} \text { Rating }_{q}+\omega_{j} \text { Ratings }
$$

onde:

$\omega_{q}$ é o peso do julgamento feito pelas agências dos determinantes quantitativos; e $\omega_{j}$ é o peso do julgamento feito pelas agências dos determinantes qualitativos, e $\omega_{q}+\omega_{j}=1$.

Temos inúmeras abordagens feitas através de modelos quantitativos ao problema de atribuição de ratings. Dentre os trabalhos poderíamos citar o trabalho de Rowland (2004) que utiliza a técnica de análise empilhada de dados (pooled data), Kim e Wu (2008) utilizam dados em painel para estimar a correlação entre o desenvolvimento dos mercados financeiros e os ratings. Canuto et alii (2004), utilizam um modelo econométrico de análise de dados em cross-section. Na linha do modelo econométrico de Cantor e Packer (1996), Ferri et alii (1999) estimam um modelo MQO com dois tipos de cardinalização para os ratings. Leichsenring (2004) estima um modelo de vetores autoregressivos (VAR) para avaliar a relação 
entre os ratings e a taxa de juros doméstica. Bone (2004) utiliza testes de estabilidade de Chow para medir a estabilidade das séries temporais de ratings soberanos emitidos pelas diversas agências, Mora (2006) utiliza regressores defasados para captar efeitos inerciais nas atribuições de ratings, dentre outros vários estudos. Entre os modelos econométricos, podemos citar o problema da cardinalização. Este problema surge da tentativa de cardinalizar os ratings para torná-los estimáveis, pois modelos econométricos são incapazes de lidar com conceitos, assim não há como introduzirmos como variável num modelo econométrico um conceito de $\mathrm{ra}$ ting. Contudo, ao cardinalizar um conceito de rating, pode-se incorrer em erros, pois cardinalizações, sejam elas lineares ou não-lineares, estabelecem uma relação quantificável entre os conceitos de ratings. Assim, uma atribuição de rating igual a 2 (dois), por exemplo, não quer dizer necessariamente que possua o dobro de risco de uma atribuição de rating igual a 1 (um).

\section{Procedimentos Metodológicos}

\subsection{Introdução}

O processo de estimação utilizado no presente trabalho foi o chamado de Redes Neurais Artificiais. Esta metodologia é inspirada nos princípios do funcionamento do cérebro humano para resolução de determinados tipos de problemas, criando a chamada inteligência artificial. Este processo de estimação é muito útil diante de problemas de reconhecimento de padrões e, portanto, de acordo com os objetivos estabelecidos, ele se torna o estimador mais apropriado para nossa análise.

A metodologia de redes neurais possui múltiplas aplicações tanto no ambiente acadêmico como no mercado, resolvendo problemas de reconhecimento de padrões como caracteres, imagens, voz, etc. São utilizadas em sistemas de auxílio a diagnósticos como em medicina, falhas mecânicas, entre outros. São amplamente usadas nas áreas de inteligência artificial de robótica e sistemas de controle, além de serem também bastante utilizadas para previsões, seja previsão de fenômenos naturais ou previsões em finanças, na qual muitos estudos desde Dutta e Shekhar (1988), Maher e Sen (1997), Arminger et alii (1997), Daniels e Kamp (1999) e Kim et alii (1993) aplicam este tipo de técnica.

Mais recentemente, temos estudos como Bennell et alii (2006) que relatam o alto grau de eficiência das redes neurais como classificadores e, comparando-as com outras técnicas estatísticas, elas se mostram superiores. Logo, percorrendo a trajetória da busca de instrumentos adequados para a análise dos ratings de risco soberano, optou-se por este método. A utilização de redes neurais, assim como a utilização de outros métodos de estimação, possui vantagens e desvantagens. Entre as vantagens, podemos apontar:

- Flexibilidade na modelagem: A hipótese de linearidade não é necessária;

- Flexibilidade estatística: Nenhuma hipótese a priori é feita sobre as distribuições de probabilidade envolvidas; 
- Categorização: As variáveis dependentes podem ser categorias qualitativas, em vez de apenas numéricas.

- Entre suas desvantagens podemos destacar:

- A rede neural pode apresentar dificuldade de configuração em relação à sua estrutura inicial e também no que se refere aos parâmetros dos algoritmos de aprendizado;

- Pode haver dificuldade em apresentar os resultados obtidos na forma da análise estatística tradicional, como intervalos de confiança, estímulo-resposta e relações de causalidade;

- Podem existir dificuldades de convergência e instabilidade inerentes aos algoritmos de otimização empregados.

Neste sentido, houve preocupação de tratar das deficiências do método para obter resultados mais expressivos e robustos sem deixar para segundo plano os aspectos teóricos do problema em questão, captando fatores inerentes ao aprendizado e reputação dos agentes no mercado através do modelo de redes neurais.

\subsection{Descrição das redes neurais artificiais}

Redes neurais são aproximadores universais de funções, como os estimadores de regressão linear e as séries de Fourier. Seu princípio é inspirado nas redes de conexões de neurônios existentes no cérebro dos animais vertebrados. Sua unidade fundamental é o neurônio, onde verificamos 3 elementos básicos:

1) Um conjunto de sinapses, caracterizadas por pesos $w_{k j}$, sendo $k$ o índice utilizado para designar o neurônio e $j$ o índice da sinapse. Um sinal $x_{j}$ na entrada da sinapse $j$ é multiplicado pelo peso sináptico $w_{k j}$.

2) Um somador, chamado de junção aditiva, que soma os sinais de entrada, ponderados pelos respectivos $w_{k j}$.

3) Uma função de transferência para restringir a amplitude da saída do neurônio.

O termo de bias $b_{k}$, é introduzido para melhorar o ajuste da função aproximada. Normalmente, o termo de bias tem um valor positivo e seu propósito é análogo ao intercepto nas regressões dos modelos econométricos.

Assim, podemos descrever um neurônio matematicamente da seguinte forma:

$$
\begin{gathered}
v_{k}=\sum_{j=1}^{m} w_{k j} x_{j}+b_{k} \\
y_{k}=\varphi\left(v_{k}\right)
\end{gathered}
$$


onde $v_{k}$ é a saída do combinador linear (somador).

Posteriormente, os neurônios são organizados em uma rede, com a saída de um servindo como entrada para outros. A Figura 1 mostra a arquitetura mais comum de rede neural, na qual os neurônios são dispostos em camadas. Na figura, os círculos simbolizam os neurônios e as setas representam as ligações sinápticas entre os neurônios

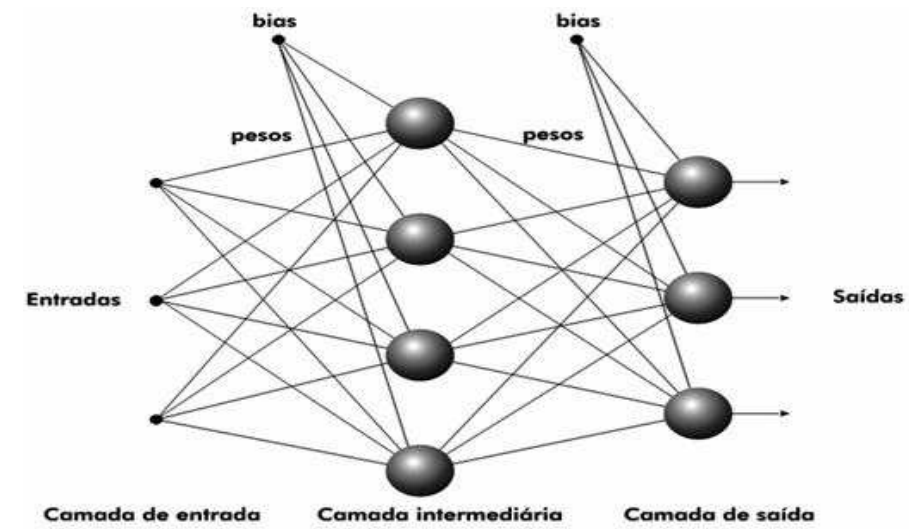

Figura 1

Rede neural com 3 camadas

Fonte: elaboração própria a partir de Veelenturf (1995).

A função de transferência ou de ativação dá o caráter não linear ao neurônio. Se $\varphi\left(v_{k}\right)=v_{k}$, então o modelo de neurônio é linear e rede neural funciona de modo análogo a um modelo de regressão linear. A função de transferência a ser escolhida pelo pesquisador é de suma importância para o bom desempenho do modelo a ser utilizado. Algumas formas de função são: função de limiar, função linear por partes, função sigmóide e função tangente hiperbólica. ${ }^{5}$

\subsection{Algoritmos de aprendizado}

Refere-se ao aprendizado por meio de regras bem definidas para solução de problemas de aprendizado. Existem muitos algoritmos específicos para aprendizagem de redes neurais, diferenciando entre si pela maneira como os pesos sinápticos são modificados. Os algoritmos de aprendizado podem se dividir em:

1) Aprendizado Supervisionado

Este método de aprendizagem consiste na adoção de uma função de custo na rede neural, onde cada vez que a rede erra a resposta desejada para o padrão de entrada, um fator externo (professor) indica quais devem ser os ajustes

\footnotetext{
${ }^{5}$ Para uma discussão mais detalhada sobre Funções Transferência consulte Fausett (1994).
} 
realizados nos pesos sinápticos de acordo com o erro a fim de diminuir esta resposta incorreta da rede. Logo, o objetivo deste tipo de aprendizado é, a cada seqüência de aprendizado, fazer com que a rede atinja uma solução estável, isto é, correções cada vez menores nos pesos sinápticos.

2) Aprendizado Não-Supervisionado

Como o próprio nome diz, é um método de aprendizado onde as redes neurais não utilizam um professor, ou seja, não há um algoritmo de correção das falhas das respostas da rede neural. Neste caso, a rede neural recebe a entrada de dados, e os organiza de maneira arbitrária em categorias. Na próxima entrada de dados, esta faz uma verificação se os dados correspondem a alguma categoria já existente e, em caso de não existir, ela cria uma ou mais categorias para classificar estes novos dados.

\subsection{O perceptron}

Uma rede neural com neurônios utilizando funções de ativação do tipo limiar é chamada Perceptron. Estes são utilizados para reconhecimento de padrões, como o reconhecimento de escrita, imagens ou mesmo de voz. Os dados de entrada consistem de um vetor $\left(x_{1}, x_{2}, \ldots, x_{m}\right)$ e a saída consiste em uma de $\mathrm{N}$ categorias previamente determinadas (por exemplo, as letras $A, B, C$, etc).

Minsky e Papert (1969) analisaram matematicamente o perceptron e demonstraram que redes de uma camada não são capazes de solucionar problemas que não sejam linearmente separáveis. Como não acreditavam na possibilidade de se construir um método de treinamento para redes com mais de uma camada, eles concluíram que as redes neurais seriam sempre suscetíveis a essa limitação.

Contudo, o desenvolvimento do algoritmo de treinamento backpropagation, por Rumelhart et alii (1986), precedido por propostas semelhantes ocorridas a partir dos 1970's, mostrou que é possível treinar eficientemente redes com camadas escondidas, resultando no modelo mais utilizado atualmente chamado de Perceptron Multi-Camadas (Multi-Layer Perceptron), treinadas com o algoritmo backpropagation (Kumar et alii, 1995).

\subsection{Multi-layer perceptron}

A regra de aprendizado utilizada para treinar uma rede multilayer perceptron é chamada Regra Delta Generalizada ou backpropagation. Quando um padrão de entrada é apresentado à rede pela primeira vez, esta produz uma saída aleatória. A diferença entre esta saída e a saída desejada constitui o erro. O backpropagation se baseia num custo ou uma função de erro baseada nesta diferença para ajustar os pesos sinápticos. A função de erro ou de performance, indicada pelo nome Least Mean Square (LMS), é o menor erro quadrado médio. A intenção do treinamento é buscar cada vez mais diminuir o valor deste erro. O método minimiza o erro e realiza iterativamente ajustes nos pesos sinápticos, passando por todos os padrões de entradas do conjunto de treinamento. Esse método é conhecido como descida de 
gradiente (gradient descent). O processo de aprendizagem prossegue, até que algum critério seja estabelecido como, um mínimo de erro global, ou uma diferença sucessiva mínima entre erros calculados para cada iteração. O backpropagation é, na verdade, um método para implementar o processo de gradiente de descida no espaço dos pesos sinápticos para o treinamento de uma rede feedforward.

$\mathrm{O}$ algoritmo de backpropagation pode apresentar alguns problemas em relação à dificuldade de aprendizado. Ao se deparar com padrões de entradas muito complexos, o treinamento é muito lento e existe o risco da rede neural cair num mínimo local.

Paralelamente, também há desvantagem em utilizar camadas escondidas, pois o aprendizado se torna muito mais difícil. A característica principal da camada escondida é que seus elementos se organizam de tal forma que cada elemento aprenda a reconhecer características diferentes do espaço de entrada, assim, o algoritmo de treinamento deve decidir que características devem ser extraídas do conjunto de treinamento.

\section{Regra de aprendizado do multi-layer perceptron}

Em conformidade com Kröse e Smagt (1996), considerando que estamos utilizando unidades com função de transferência não-linear, temos que generalizar a regra delta para este tipo de função de transferência.

A função de transferência é uma função diferenciável da entrada total, dada por:

$$
y_{k}^{p}=F\left(s_{k}^{p}\right)
$$

onde:

$y_{k}^{p}$ é a saída produzida pela rede neural num certo momento do processo de aprendizado para um dado padrão de entrada $p$;

$s_{k}^{p}$ é o número de neurônios utilizados pela rede neural num certo momento do processo de aprendizado para um dado padrão de entrada $p$, isto é:

$$
s_{k}^{p}=\sum_{j} w_{j k} y_{j}^{p}+b_{k}
$$

Para obter a generalização correta da regra delta, é necessário definir:

$$
\Delta_{p} w_{j k}=-\gamma \frac{\partial E^{p}}{\partial w_{j k}}
$$

onde:

$\Delta_{p}$ é uma constante que indica o quanto deve o peso sináptico alterar num certo momento do processo de aprendizado para um dado padrão de entrada $p$;

$\gamma$ é uma constante de proporcionalidade;

$E^{p}$ é a soma dos erros quadrados num certo momento do processo de aprendizado para um dado padrão de entrada $p$. 
Logo, podemos definir $E^{p}$ como:

$$
E^{p}=\frac{1}{2} \sum_{o=1}^{N_{o}}\left(d_{o}^{p}-y_{o}^{p}\right)^{2}
$$

onde $d_{o}^{p}$ é a saída desejada para unidade o quando o padrão de entrada $p$ é mantido.

Continuamos definindo $E=\sum_{p} E^{p}$ como a soma dos erros quadrados. Podemos escrever:

$$
\frac{\partial E^{p}}{\partial w_{j k}}=\frac{\partial E^{p}}{\partial s_{k}^{p}} \frac{\partial s_{k}^{p}}{\partial w_{j k}}
$$

Pela equação (6) podemos observar que o segundo fator do lado direito da equação (8) é:

$$
\frac{\partial s_{k}^{p}}{\partial w_{j k}}=y_{j}^{p}
$$

Podemos definir:

$$
\delta_{k}^{p}=-\frac{\partial E^{p}}{\partial s_{k}^{p}}
$$

Alterando a regra de atualização, que é equivalente à regra delta, temos que o resultado é uma descida de gradiente na superfície de erro. Assim, as alterações nas mudanças dos pesos sinápticos são feitas de acordo com:

$$
\Delta_{p} w_{j k}=\gamma \delta_{k}^{p} y_{j}^{p}
$$

Desta forma, o objetivo é definir qual deveria ser $\delta_{k}^{p}$ para cada unidade $k$ da rede neural. O resultado derivado agora, é que há uma computação recursiva simples destes $\delta^{\prime} s$ que podem ser implementados propagando sinais de erro para trás pela rede neural.

Para computar $\delta_{k}^{p}$, aplica-se a regra da cadeia para escrever esta derivada parcial como produto de dois fatores, um que reflete a mudança do erro como uma função da saída da unidade $k$ e outro que reflete a mudança da saída como uma função de mudanças na entrada. Podemos escrever:

$$
\delta_{k}^{p}=-\frac{\partial E^{p}}{\partial s_{k}^{p}}=-\frac{\partial E^{p}}{\partial y_{k}^{p}} \frac{\partial y_{k}^{p}}{\partial s_{k}^{p}}
$$

Substituindo a equação (3) no segundo fator do lado direito da equação (12), temos:

$$
\frac{\partial y_{k}^{p}}{\partial s_{k}^{p}}=F^{\prime}\left(s_{k}^{p}\right)
$$


A equação (13) é a derivada da função $F$ para a k-ésima unidade, avaliada na entrada

$s_{k}^{p}$ para a unidade $k$. Para substituir a equação (13) no primeiro fator do lado direito da equação (12), em primeiro lugar, tomamos que a unidade $k$ é uma unidade de saída $k=o$ da rede neural. Neste caso, segue-se que da definição de $E^{p}$ definida pela equação (7) que:

$$
\frac{\partial E^{p}}{\partial y_{o}^{p}}=-\left(d_{o}^{p}-y_{o}^{p}\right)
$$

Substituindo a equação (15) na equação (12), chegamos a:

$$
\delta_{o}^{p}=\left(d_{o}^{p}-y_{o}^{p}\right) F_{o}^{\prime}\left(s_{o}^{p}\right), \quad \forall o
$$

Em segundo lugar, se $k$ não é uma unidade de saída, mas uma unidade escondida $k=h$, não é conhecida a contribuição da unidade ao erro da saída da rede neural. Porém, a medida de erro pode ser escrita como uma função dos pesos da entrada da camada escondida para a camada de saída; $E^{p}=E^{p}\left(s_{1}^{p}, s_{2}^{p}, s_{3}^{p}, \ldots, s_{j}^{p}\right)$ e utilizando novamente a regra da cadeia podemos escrever:

$$
\begin{aligned}
\frac{\partial E^{p}}{\partial y_{h}^{p}} & =\sum_{o=1}^{N_{o}} \frac{\partial E^{p}}{\partial s_{o}^{p}} \frac{\partial s_{o}^{p}}{\partial y_{h}^{p}}=\sum_{o=1}^{N_{o}} \frac{\partial E^{p}}{\partial s_{o}^{p}} \frac{\partial}{\partial y_{h}^{p}} \sum_{j=1}^{N_{h}} w_{k o} y_{j}^{p} \\
& =\sum_{o=1}^{N_{o}} \frac{\partial E^{p}}{\partial s_{o}^{p}} w_{k o}=-\sum_{o=1}^{N_{o}} \delta_{o}^{p} w_{h o}
\end{aligned}
$$

Substituindo a equação (16) na equação (12):

$$
\delta_{h}^{p}=F^{\prime}\left(s_{h}^{p}\right) \sum_{o=1}^{N_{o}} \delta_{o}^{p} w_{h o}
$$

As equações (16) e (17) têm um procedimento recursivo para computar os $\delta^{\prime} s$ para todas as $k$ unidades da rede neural que é usada para ajustar as mudanças dos pesos sinápticos de acordo com equação (17). Este procedimento constitui a regra de delta generalizada para uma rede feed-forward de unidades não-lineares. ${ }^{6}$

\section{Treinamento resilient-propagation (rprop)}

Ao contrário o algoritmo de backpropagation tradicional, o algoritmo Resilient-Propagation também chamado de RPROP, desenvolvido inicialmente por Riedmiller e Braun (1993), utiliza apenas sinais de derivadas parciais para ajustar os coeficientes dos pesos sinápticos. Este algoritmo utiliza o método de

\footnotetext{
${ }^{6}$ Para detalhar melhor as propriedades dos algoritmos de aprendizagem, consulte alguns teoremas descritos em Veelenturf (1995), Kröse e Smagt (1996), Block (1962) e Novikoff (1962).
} 
iterações e reajusta os pesos sinápticos após todos os padrões da sub-amostra de treinamento serem apresentados à rede.

O algoritmo RPROP ajusta os pesos sinápticos da rede neural seguindo a regra:

$$
\Delta_{i j}^{(t)}=\left\{\begin{array}{c}
\eta^{+} \Delta_{i j}^{(t)}, \frac{\partial E^{(t)}}{\partial w_{i j}} \frac{\partial E^{(t-1)}}{\partial w_{i j}}>0 \\
\eta^{-} \Delta_{i j}^{(t)}, \frac{\partial E^{(t)}}{\partial w_{i j}} \frac{\partial E^{(t-1)}}{\partial w_{i j}}<0
\end{array}\right\}
$$

Segundo Akobir (2007), se em determinado momento o peso sináptico correspondente da derivada parcial $w_{i j}$ inverter seu sinal, é por que sua última modificação foi elevada e o algoritmo perdeu o mínimo local. Então, o tamanho da modificação deveria diminuir determinado pelo fator $\eta^{-}$e o valor prévio do coeficiente do peso sináptico restabelecido. Em outras palavras, esta modificação deveria ser desfeita.

$$
\Delta w_{i j}(t)=\Delta w_{i j}(t)-\Delta_{i j}^{(t-1)}
$$

Se o sinal da derivada parcial não mudou, então o ajuste deveria ser aumentado por $\eta^{+}$para alcançar mais rapidamente a convergência. Fixados os fatores de diminuição $\eta^{-}$e de aumento $\eta^{+}$podemos manter as configurações globais da rede de neural inalteradas. Logo, este fato poderia ser uma vantagem do algoritmo Resilient-Propagation em relação ao algoritmo de backpropagation tradicional (Akobir, 2007).

Para evitar valores de pesos sinápticos muito altos ou muito baixos, o valor de ajuste é determinado acima por $\Delta_{\max }$ e abaixo por $\Delta_{\min }$.

A regra demonstrada pela equação (20) é utilizada para encontrar o valor de ajuste dos pesos sinápticos:

$$
\Delta w_{i j}(t)=\left\{\begin{array}{l}
-\Delta_{i j}^{(t)}, \frac{\partial E^{(t)}}{\partial w_{i j}}>0 \\
+\Delta_{i j}^{(t)}, \frac{\partial E^{(t)}}{\partial w_{i j}}<0 \\
0, \frac{\partial E^{(t)}}{\partial w_{i j}}=0
\end{array}\right\}
$$

Se a derivada é positiva, isto é, o erro aumenta, o coeficiente do peso sináptico é diminuído pelo valor de ajuste, caso contrário é aumentado. Logo, a equação ilustra a forma como os pesos são ajustados:

$$
w_{i j}(t+1)=w_{i j}(t)-\Delta w_{i j}(t)
$$

\section{Regularização}

Além da função de performance da rede neural $L M S$, definida anteriormente para o caso do Multi-Layer Perceptron pela equação (17), temos modificações 
destas funções de performance. O objetivo destas modificações é melhorar a performance de generalização da rede neural, a qual é chamada de regularização.

\section{Função de Performance modificada}

Uma definição alternativa para a função tradicional de performance utilizada para treinar uma rede neural do tipo feedforward é a LMS descrita em Demuth e Beale (1998).

$$
F=m s e=\frac{1}{N} \sum_{i=1}^{N}\left(e_{i}\right)^{2}=\frac{1}{N} \sum_{i=1}^{N}\left(t_{i}-a_{i}\right)^{2}
$$

Onde a sigla mse significa o erro-quadrado-médio É possível melhorar o poder de generalização da rede neural modificando a função de performance somando um termo que consiste na média da soma dos quadrados dos pesos e bias da rede neural:

$$
m s e r e g=\gamma m s e+(1-\gamma) m s w
$$

onde $\gamma$ é a razão de performance e,

$$
m s w=\frac{1}{n} \sum_{j=1}^{n} w_{j}^{2}
$$

Ao usar esta função de performance a rede irá diminuir seus pesos sinápticos e bias, e isto forçará a resposta de rede a ser mais suave e menos sujeita a problemas de overfitting.

O problema com a regularização é que é difícil determinar um valor ótimo para o parâmetro da razão de performance. Se escolhermos um valor para este parâmetro elevado, podemos incorrer em overfitting. Se esta razão for muito pequena, a rede não vai generalizar adequadamente a amostra de treinamento.

Segundo Kaastra e Boyd (1996), o problema de overfitting ocorre quando um modelo de predição, como o de redes neurais, possui muito poucos graus de liberdade. Este problema causa perda de poder de generalização das redes neurais fazendo com que esta incorra em memorização de idiossincrasias de observações individuais e perda do poder predição. Logo, um modelo de redes neurais robusto deve analogamente aos modelos econométricos, seguir o critério da parcimônia, o que, além de diminuir o custo computacional da rede neural, aumenta sua capacidade de generalização. 


\section{Seleção e Tratamento da Amostra de Dados}

A amostra de ratings utilizada compreende os ratings de longo prazo em moeda estrangeira atribuídos a países emergentes pela agência Standard \& Poor's, a partir de 1975, fornecidos pelo relatório de 2 de novembro de 2005. Das 23 escalas de ratings atribuídas por esta agência apresentadas na Tabela 1, na amostra utilizada existem 18 escalas diferentes. ${ }^{7}$

É importante ressaltar que o início da amostra temporal de ratings se dá a partir em 1975, porém isso não quer dizer que todos os países tenham atribuições de ratings se iniciando em 1975. Cada país da amostra foi incluso de acordo com a sua primeira atribuição de rating. As variáveis utilizadas no trabalho como determinantes macroeconômicos das atribuições de ratings foram coletadas nas estatísticas de indicadores de desenvolvimento dos países emergentes publicadas pelo Banco Mundial.

A publicação chamada Indicadores de Desenvolvimento do Mundo realizada pelo Banco Mundial, possui observações com freqüência anual e término em 2003. Como estas observações fizeram referência às estatísticas de final de período, utilizamos as atribuições de ratings também de final de período para o caso daqueles países que receberam mais de uma atribuição de rating por ano. Portanto, para os países que a agência Standard \& Poor's atribuiu mais de uma escala de rating no mesmo ano, utilizamos nas estimações deste trabalho apenas observações da última atribuição de rating daquele ano.

Além disso, os outliers da amostra foram excluídos, o que não gera nenhuma perda de informação em nosso modelo e, diferentemente dos modelos econométricos nos quais existem tratamentos para este tipo de problema, os outliers em redes neurais podem e devem ser excluídos da amostra. A razão pela qual eles são excluídos da amostra é simples. Na fase de treinamento das possíveis arquiteturas utilizadas na estimação final do trabalho, a inclusão de outliers pode dificultar este treinamento, o que pode causar, entre outras consequiências, perda de robustez do modelo.

\section{Aspectos de Natureza Metodológica e Análises}

\subsection{Implementação da Rede Neural Artificial}

Nesta seção, foram enumerados alguns passos básicos da implementação da rede neural utilizados no software MATLAB $R$ para obter simulações depois de definidos a seleção e tratamento da amostra de dados. Estes são constituídos pela fase de treinamento e teste da rede neural.

Segundo Kaastra e Boyd (1996), uma prática comum é dividir a amostra de dados em duas sub-amostras, denominadas amostra de treinamento e de teste. A amostra de treinamento é a maior em tamanho e compreende cerca de $90 \%$ do tamanho total da amostra de dados. Os $10 \%$ restantes é deixado para o teste. O

\footnotetext{
${ }^{7}$ As escalas AA+, AA-, C, SD e D não foram encontradas na amostra utilizada de avaliações de ratings.
} 
pesquisador deve utilizar o tipo de rede neural que obteve melhor desempenho na fase de treinamento e teste, isto é, a rede neural que possuir menor erro de predição.

A escolha sobre qual tipo de função de treinamento utilizar na rede neural, assim como outras escolhas na elaboração de uma arquitetura de rede neural, é um processo também experimental. Logo, dado o critério de erro ${ }^{8}$ da rede neural na fase de treinamento, escolhe-se a função que melhor se adaptou à amostra de dados apresentada.

A amostra de teste pode ser definida a partir de duas abordagens diferentes. Ela pode ser escolhida aleatoriamente a partir da amostra de treinamento ou pode ser definida com observações mais recentes que sucedem as observações da amostra de treinamento (para o caso de séries de tempo). Uma vantagem do uso da segunda abordagem é testar a rede com observações mais recentes que podem ser informações mais relevantes para a explicação do problema a ser tratado pelas redes neurais (Haykin, 2001).

A arquitetura da rede neural, isto é, o número de camadas de neurônios e o total de neurônios por camada, assim como qual tipo de interconexão entre estas dependem da natureza e do tamanho da amostra de dados na qual se pretende utilizar a rede neural. O número de neurônios utilizados na entrada e na saída da rede neural é, respectivamente, o número de variáveis independentes e dependentes do modelo a ser estimado.

O número de camadas ideal da rede neural deve ser tal que ela seja tão grande quanto necessária para conseguir obter as representações necessárias, mas ao mesmo tempo pequena o suficiente para se obter um treinamento mais rápido. Não existem regras claras para se definir quantas unidades devem existir nas camadas escondidas, quantas camadas, ou como devem ser as conexões entre essas unidades (Siu et alii, 1995).

Teoricamente, uma rede neural com uma camada de neurônios escondida com um número suficiente de neurônios nesta camada, seria capaz de aproximar qualquer tipo de função contínua. Na prática, redes neurais com uma ou duas camadas de neurônios escondidas são amplamente utilizadas e possuem performances bastante satisfatórias.

Deve-se ressaltar que aumentar tanto o número de camadas como também o número de neurônios da rede neural, além de aumentar o custo computacional, também expõe a arquitetura da rede neural a problemas de overfitting.

\subsection{Análise dos Resultados}

Este trabalho se destinou a fazer inferências sobre o comportamento dos ratings de risco soberano a partir dos fundamentos macroeconômicos. Desta forma, nesta seção, foi detalhado inicialmente os aspectos técnicos da aplicação dos procedimentos metodológicos sobre os dados empíricos e, logo após, procurou-se, à luz da teoria econômica, discutir estes resultados.

${ }^{8} \mathrm{O}$ critério a ser adotado para se estabelecer desempenho da rede neural pode ser o $M S E, S S E$ ou MSEREG. 
As análises foram feitas a partir de variações do modelo de redes neurais artificiais Multi Layer-Perceptron (MLP). O motivo pelo qual foi utilizado tal procedimento justifica-se pelo tipo de problemática, neste caso uma classificação das atribuições de ratings de risco soberano, onde problemas envolvendo classificação constituem a principal aplicação da MLP.

Aplicou-se no processo de treinamento da rede neural a aprendizagem do tipo supervisionada. Testaram-se diversas redes neurais e, de acordo com o caráter experimental das estimações por este procedimento metodológico, partiu-se de uma arquitetura de rede neural composta por onze neurônios na primeira camada, isto é, onze variáveis macroeconômicas compunham o input da rede. A saída ou output da rede neural foi composto inicialmente por 18 neurônios, pois na amostra de ratings da Standard \& Poor's utilizada nas estimações, tínhamos 18 escalas de ratings.

Especificamente, testamos arquiteturas de redes neurais do tipo feedforward e cascade-forward. ${ }^{9}$ Foi observado que as arquiteturas feedforward obtiveram desempenho ligeiramente superior ao desempenho das arquiteturas cascade-forward, assim optou-se por definir os resultados finais a partir da primeira arquitetura.

De acordo com o princípio da parcimônia, para encontrar uma rede neural robusta e evitar problemas como a presença de overfitting, é recomendado construir inicialmente uma rede neural com apenas uma camada escondida e com 10 neurônios nesta camada, aumentando gradativamente o número de neurônios de acordo com os testes de performance da rede. Além disso, testou-se também redes com mais de uma camada escondida o que não aumentou a performance da rede. A rede neural utilizada nas estimações do trabalho foi uma rede com uma camada escondida composta por 40 neurônios, uma camada de entrada composta por 4 neurônios e uma camada de saída composta por 8 neurônios.

O tipo de função de aprendizado constitui também uma peça importante da rede neural e a função utilizada na estimação deste trabalho foi a aprendizagem chamada backpropagation com uma constante de momentum, descrita na seção de procedimentos metodológicos.

Foram testados diversos tipos de algoritmos de treinamento, onde os mais importantes foram Levenberg-Marquardt, ${ }^{10}$ backpropagation com uma constante de momentum e Resilient-Propagation. ${ }^{11} \mathrm{O}$ tipo de treinamento de melhor performance seja pelo critério de melhor predição ou por possuir menor custo computacional, foi o Resilient-Propagation o que nos levou a utilizá-lo na estimação do trabalho, em outras palavras, a performance do algoritmos de treinamento Resilient-Propagation sobre a base de dados utilizada foi superior quando tomamos os critérios enumerados anteriormente.

\footnotetext{
${ }^{9}$ Ver mais sobre arquiteturas do tipo cascade em Arbib (2003, p. 648).

${ }^{10}$ Descrito em detalhes em Hangan e Menjah (1994).

${ }^{11}$ Descrito pela equação (21).
} 
A mensuração da performance da rede neural foi realizada pela função msereg definida pela equação (23) que permitiu a regularização da performance ótima da rede. O valor para o parâmetro $\gamma$ escolhido onde a rede neural obteve uma performance satisfatória foi $\gamma=1,0$.

Após testes, foi definida a função de transferência ou ativação entre os neurônios da rede neural como uma função do tipo tangente hiperbólica. Adicionalmente, testou-se qual o número ótimo de iterações a partir da performance do erroquadrado-médio apresentado pelas diferentes redes neurais testadas e, de acordo com esta performance, escolheu-se não mais que cerca de cem iterações necessárias para convergência do erro-quadrado-médio para um valor mínimo.

Das 18 escalas de ratings trabalhadas inicialmente na rede neural, optou-se por deixar apenas 8 , pois observou-se que, com este número de escalas, a performance da rede foi mais robusta. Embora esta decisão realizada durante a pesquisa possa ser naturalmente questionada, deve-se ressaltar novamente que o objetivo do estudo foi compreender o funcionamento do mercado de ratings para após sugerir, neste caso também se utilizando de cenários, possíveis medidas para diminuição ou mesmo eliminação de alguns gargalos presentes nestes mercados de crédito. Assim, em detrimento à classificação composta por muitas classes e subclasses, que demandam esforço adicional e por outro lado levam à dúvida no que se refere à robustez dos resultados, seguiu-se os preceitos da parcimônia, eliminando completamente a presença de overfitting. A simbologia escolhida, por ordem crescente de risco, da escala de ratings utilizada na rede foi: $A, A A, A A A, B, B B, B B B$, $C C$ e $C C C$.

Foi realizada uma análise de sensibilidade da rede aos inputs que acrescentaram pouca informação ao modelo, análise esta presente nos modelos econométricos como o método stepwise. ${ }^{12}$ Desta forma, as variáveis escolhidas para serem utilizadas na estimação foram: nível de reservas totais como percentual do produto; dívida externa total como percentual das exportações de bens e serviços; balança externa de bens e serviços como percentual do produto; e taxa de crescimento do produto per capita. Em outras palavras, este modelo permitiu escolher as variáveis mais importantes na determinação da avaliação dos ratings de risco soberano.

As Figuras 2 e 3 ilustram respectivamente, as performances do treinamento e teste realizados na rede neural escolhida. Na Figura 2, a linha declinante representa a performance de treinamento de rede, na qual é possível observar que o erro de predição da rede neural atinge um nível satisfatório em torno de 0,13944 na centésima iteração realizada pelo treinamento.

${ }^{12}$ Este método consiste em reduzir a necessidade de computação intensiva para selecionar o melhor subconjunto de regressores, adicionando ou reduzindo algum regressor. Ver mais em Greene (2002). 


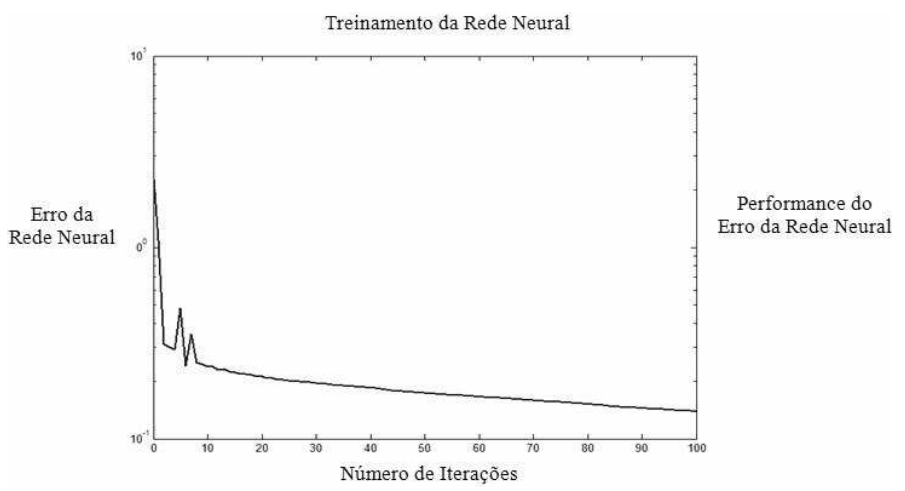

Figura 2

Performance do treinamento da rede neural escolhida

Na Figura 3, tem-se a média de erros de predição da rede neural utilizada, seu erro máximo e seu erro mínimo de acordo com a legenda da figura.

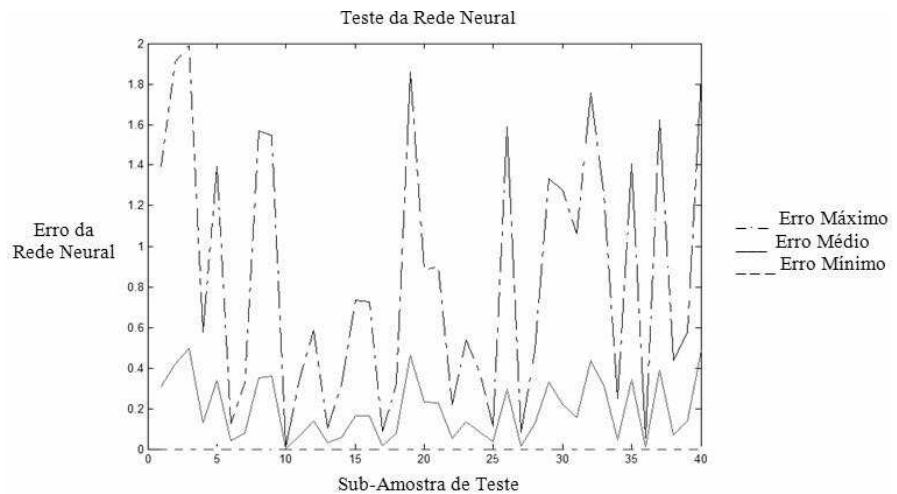

Figura 3

Performance do teste da rede neural escolhida

Fonte: elaboração própria a partir de dados da Standard \& Poor's e World Bank.

O erro de predição da rede neural ilustrado pelos pontos mais elevados das linhas de erro constitui a falha da rede neural em predizer, dados os fundamentos macroeconômicos apresentados a ela, a atribuição de rating. Assim, observou-se que a rede consegue com certa robustez, para oito escalas de ratings, predizer as atribuições de ratings a partir dos 4 tipos de variáveis macroeconômicas.

Teoricamente, de acordo com Kaastra e Boyd (1996), uma rede neural com uma camada escondida consegue aproximar qualquer tipo de função. Contudo, ao 
aplicar redes neurais dos tipos descritas anteriormente aos determinantes quantitativos empíricos dos ratings de risco soberano de longo prazo, examinou-se certo grau de dificuldade de predição da rede neural que motivou a diminuição o número de escalas de ratings da saída da rede. Embora este problema não tenha prejudicado significativamente a análise deste trabalho ele surgiu por que a rede escolhida não conseguiu, a partir dos dados macroeconômicos, fazer distinção entre 18 escalas diferentes de ratings.

Possíveis explicações surgiram para tal problema. Como apontado por diversos estudos empíricos citados ao longo do trabalho, por exemplo, Partnoy (2002), Ferri et alii (1999), Bone (2004), Cantor e Packer (1996), Canuto et alii (2004), mesmo para os determinantes quantitativos, é difícil encontrar uma relação direta entre estes e os ratings atribuídos pela Standard \& Poor's, por causa do grande número de critérios adotados por esta agência. Pois, os ratings são construídos com base em análises das conjunturais sobre a vida econômica, social e política dos países e, por este motivo, podem ser subjetivos porque envolvem julgamentos de analistas sobre uma grande quantidade de variáveis.

Além disso, estes trabalhos tratam de inúmeros problemas envolvendo os $\mathrm{ra}$ tings como problemas de ordem legal dos mercados financeiros como discutido no trabalho de Partnoy (2002), ou as antecipações das mudanças das variáveis econômicas às mudanças nas atribuições dos ratings como discutido neste mesmo trabalho e nos trabalhos de Bone (2004) e Ferri et alii (1999). Neste último, é postulada a idéia da existência de uma regra procíclica das agências de rating prolongando os efeitos de crises sobre as economias através de comportamentos excessivamente conservadores caracterizados por atribuírem ratings como remédio às crises financeiras. Isto é, quando as agências não conseguem antever uma crise sinalizando ao mercado o perigo desta, elas atribuem ratings na tentativa de remediá-la, porém o que elas conseguem é prolongá-la, pois os novos ratings atribuídos fazem com que os investidores componham uma carteira de investimentos de menor risco, vendendo os títulos dos países envolvidos nesta crise, provocando uma perda de liquidez destes fazendo com que esta se prolongue.

Deve-se ressaltar que a dificuldade de ajustamento de um modelo de redes neurais reflete a possibilidade de haver atribuições de ratings em desacordo com os fundamentos macroeconômicos dos países emergentes que compõem a amostra de dados deste trabalho. O que remete à idéia de que o peso dos determinantes qualitativos das atribuições de ratings para este grupo de países é instável, implicando num julgamento por parte das agências ainda mais subjetivo.

Do ponto de vista dos governantes destes países, a tarefa de se identificar a causa de um julgamento ruim das agências se torna mais difícil em conseqüência desta parcela dos determinantes qualitativos não possuir estabilidade. Na outra mão, estes países ao buscar recursos no mercado internacional, têm que manter elevadas taxas de juros em face aos julgamentos das agências. $\mathrm{O}$ efeito mais perceptível deste fato no lado real da economia, é que elevadas taxas de juros levam a um retardo do investimento e logo, do crescimento econômico. 
Mesmo com os problemas envolvendo a questão dos ratings, conseguiu-se chegar a um tipo de rede neural que realiza predições relativamente bem para 8 escalas de ratings a partir de 4 variáveis macroeconômicas como mencionado anteriormente.

A partir da escolha da rede neural de melhor poder de generalização, foram simulados cenários para a economia brasileira, a partir de mudanças nos comportamentos dos fundamentos macroeconômicos que compõem os inputs da rede neural, nos quais o risco soberano diminui e segue na escala de B para BBB.

Conforme mencionado anteriormente, com as simulações de cenários foi possível um exercício de estática comparativa para saber quais variáveis estavam mais correlacionadas com o fenômeno dos ratings e se as direções destas correlações estão em acordo com a teoria econômica contemporânea que contemplam aspectos microeconômicos dos contratos sob informações assimétricas.

Mais precisamente, foram tomadas quatro variáveis macroeconômicas citadas anteriormente para escolha da rede neural e simularam-se mudanças nestas variáveis para o ano de $2003^{13}$ de modo que o Brasil obtivesse conceito de investment grade, o que foi publicado recentemente pelas agências Standard \& Poor's e Fitch IBCA. Todavia, a agência Moody's Investor Service não seguiu esta mudança de avaliação, pois seus analistas estão temerosos em relação à variável Dívida Externa. De acordo com os analistas desta agência, o Brasil, por figurar entre os líderes no ranking dos países mais afetados historicamente com crises externas, deve trabalhar para diminuir mais acentuadamente esta variável.

As simulações consistiram na geração aleatória pela rede neural escolhida, com distribuição uniforme, de 1.000 cenários que gerariam um rating de risco igual a BBB a partir dos valores observados das 4 variáveis macroeconômicas no ano de 2003.

Inicialmente, foram simuladas modificações nas observações de apenas uma variável macroeconômica de cada vez. Contudo, notou-se que os ratings se manteveram inelásticos a estas modificações. Isto pode demonstrar que, para que haja uma nova atribuição de rating de risco soberano, seja necessário um conjunto de modificações nos fundamentos macroeconômicos e não apenas a modificação de apenas um destes fundamentos.

Diante disso, a partir dos cenários simulados, obteve-se uma média de possíveis realidades macroeconômicas para a economia brasileira em 2003. A Tabela 2 resume estes tipos de cenários simulados, onde na primeira coluna de dados, têmse os valores observados das variáveis macroeconômicas em 2003 e, nas demais colunas, os tipos de cenários.

${ }^{13}$ Diante da indisponibilidade de dados macroeconômicos mais recentes pelo Banco Mundial, as análises do presente trabalho foram realizadas com base neste ano. 
Tabela 2

Simulações de cenários macroeconômicos

\begin{tabular}{lccccc}
\hline \multicolumn{1}{c}{ Variáveis (em \%) } & $\begin{array}{c}\text { Observações } \\
2003\end{array}$ & Cenário 1 & Cenário 2 & Cenário 3 & Cenário 4 \\
\hline Balança externa / Produto & 6 & 6,4 & 7,6 & 7,6 & 7,6 \\
Dívida externa total / Exportações & 265 & 235 & 235 & 235 & 265 \\
Crescimento do produto per capita & -1 & 2 & 1 & 2 & 2 \\
Nível de reservas totais / Produto & 9 & 15,75 & 15,75 & 13,75 & 15,75 \\
\hline Fonte: Elaboração própria a partir de dados da Stancard \& Poor's e World Bank.
\end{tabular}

A partir das simulações destes 4 diferentes cenários, percebeu-se inicialmente que, para o Brasil alcançar uma nova atribuição de rating de risco, as 4 variáveis econômicas que fazem parte dos fundamentos macroeconômicos dos ratings devem se alterar.

De maneira geral, observou-se que mudanças mais acentuadas em alguns fundamentos permitem que outros fundamentos se modifiquem menos ou se mantenham constantes de modo que, no conjunto, melhoras dos fundamentos descritas nos cenários implicam num upgrade do conceito de rating. Isto é, políticas que agem no sentido de melhorar o Balanço de Pagamentos fazem com que as condições de captação de crédito no mercado externo melhorem. O que se traduz em termos reais na possibilidade de maior crescimento e desenvolvimento, via diminuição do spread da taxa de juros em relação às taxas de juros pagas pelo tesouro americano.

Para que haja uma mudança da atribuição de rating de risco para a economia brasileira, há uma combinação das mudanças dos fundamentos macroeconômicos. Desta forma, o crescimento do produto per capita e a razão do nível de reservas totais como percentual do produto se mostram variáveis importantes, pois em todos os cenários, estas se elevam mais acentuadamente.

Com exceção do cenário 4 , onde todas as variáveis que se relacionam diretamente com a escala de rating de risco soberano, aumentam mais acentuadamente, a dívida externa total como percentual das exportações de bens e serviços diminui. Logo, esta variável também se mostra importante para que as condições de captação de recursos pelo Brasil nos mercados internacionais melhorem.

O aumento da razão do nível de reservas totais como percentual do produto também se mostra sempre crescente de acordo com a melhora de atribuição de rating. Notou-se que o aumento do nível de reservas é importante para melhorar as condições de crédito no mercado internacional.

Uma das características dos fundamentos macroeconômicos de todos os cenários simulados, é que todos são possíveis de serem alcançados no curto prazo através de instrumentos de políticas econômicas. Contudo, não faz parte dos objetivos do presente trabalho discutir quais as políticas econômicas ou quais os instrumentos destas, devem ser utilizados. 


\section{Conclusão}

Os problemas em torno da assimetria de informação na economia e suas conseqüências diretas sobre as vidas das pessoas, podem ser mensurados pela quantidade e qualidade dos estudos produzidos em torno deste tipo de temática.

Diante do desenvolvimento e maior integração entre os mercados financeiros mundiais, instituições e dispositivos que têm por objetivo minimizar os transtornos gerados pela assimetria de informações são de muita importância. Desta forma, a magnitude da importância dos ratings na economia, como síntese clara e simples de informações sobre as futuras condições de pagamento de um emitente de dívida, também é incomensurável. Haja vista que as condições de captação de recursos no mercado estão fortemente atreladas a eles como foi discutido por Partnoy (2002).

Uma determinada atribuição de rating para um emitente de dívida soberano como um país, por exemplo, pode levá-lo a conseqüências permanentes e desastrosas ou levá-lo a uma marcha rumo ao desenvolvimento sócio-econômico via aumento da sua taxa de investimentos. No caso de países emergentes como o Brasil, que têm ampla necessidade de captação de recursos no mercado externo para concretizar projetos de investimentos, sejam privados ou estatais, esta atribuição pode conter um peso substancialmente maior, pois eleva o custo de captação destes recursos. Isso pode ocorrer porque dada uma atribuição de rating de risco soberano elevada, os dirigentes da economia brasileira serão obrigados a aumentar o prêmio de risco pago por eles, isto é, a taxa de juros paga pelos papéis e títulos financeiros emitidos pelo governo brasileiro.

Em outras palavras, o governo será obrigado, se por hipótese houver uma elevação do risco de crédito concedido para o Brasil no mercado internacional, a aumentar o spread de prêmio pago entre títulos do governo brasileiro e os títulos do governo norte-americano, causalidade esta apresentada pelo trabalho de Cantor e Packer (1996).

Mesmo levando em consideração características das agências de ratings que as justificam como fornecedoras deste tipo de serviço na economia, críticas tanto do meio acadêmico quanto do mercado, têm surgido no sentido de atacar sua capacidade preditiva frente a eminências de crises financeiras. Logo, aplicar-se uma ferramenta interessante como as redes neurais artificiais neste tipo de problema se torna fundamental.

Assim, a utilização de redes neurais artificiais no aprendizado da regra que rege o processo de atribuição de rating de risco soberano objetivou elucidar um processo decisório que, como levantado por Ferri et alii (1999), funciona de maneira vaga. Além disso, utilizou-se esta regra na construção de cenários para a economia brasileira a fim de saber como se modificariam as variáveis macroeconômicas determinantes destas atribuições. 
Vimos que 4 variáveis macroeconômicas estão mais diretamente conectadas a estas atribuições. São elas: o nível de reservas totais como percentual do produto, a dívida externa total como percentual das exportações de bens e serviços, a balança externa de bens e serviços como percentual do produto e a taxa de crescimento do produto per capita.

Das 18 escalas diferentes de ratings que inicialmente faziam parte do output da rede neural, conseguiu-se através de uma arquitetura do tipo feedforward, com uma camada escondida composta por 40 neurônios, chegar-se a 8 escalas diferentes de ratings. Isto se deu em parte à dificuldade de implementação de métodos quantitativos à problemática envolvendo ratings de risco soberano como amplamente relatado na literatura e, em parte, ao maior refinamento da rede neural. Como foi descrito, foram testadas diversas variações de composições de arquiteturas de redes.

Os cenários construídos nos mostraram que combinações de modificações dos fundamentos macroeconômicos foram necessárias para que o Brasil saltasse da escala de atribuição de rating para investment grade. Além disso, notou-se que o sentido das modificações das variáveis foi de acordo com a teoria econômica recente de contratos fundamentada nos seus aspectos microeconômicos e que as magnitudes destas modificações podem ser alcançadas no curto ou médio prazo.

Dado o processo experimental de construção de uma arquitetura de rede neural adequada, pode-se concluir que a busca de maior refinamento deste, se torna uma preocupação com a qual o pesquisador que o aplica terá sempre que lidar. Deve-se ressaltar que o melhor modelo de redes neurais será sempre tangenciado.

Logo, o trabalho buscou alcançar seu principal propósito no sentido de auxiliar os formuladores de políticas econômicas que têm por objeto melhorar as condições de crédito no mercado internacional, a definir políticas com mais subsídio informacional, pois a comprovação científica é uma importante informação para processos de decisão.

\section{Referências}

Akobir, S. (2007). Mathematical apparatus of the RPROP learning algorithm. BaseGroup labs. Disponível em: http://www.basegroup.ru/neural/rprop.en.htm Acesso em: 30 jan 2007.

Andritzky, J. R., Bannister, G. J., \& Tamirisa, N. T. (2007). The impact of macroeconomic announcements on emerging market bonds. Emerging Markets Review, 8:20-37.

Arbib, M. A. (2003). The Handbook of Brain Theory and Neural Networks. The MIT Press, London, England, 2 edition. 648 p.

Arminger, G., Enache, D., \& Banne, T. (1997). Analyzing credit risk data: A comparison of logistic discrimination, classification tree analysis and feedforward networks. Computational Statistics, 12(2):293-310. 
Arnott, R. J. \& Stiglitz, J. E. (1988). The basic analytics of Moral Hazard. Scandinavian Journal of Economics, 12(2):293-310.

Bennell, J. A., Crabbe, D., \& Thomas, S. (2006). Modelling sovereign credit ratings: Neural networks versus ordered probit. Expert Systems with Apllications, 30:415-425.

Block, H. D. (1962). The perceptron: A model for brain functioning. I Review of Modern Physics, 34:126-135.

Bone, R. B. (2002). Análise crítica dos fundamentos dos ratings soberanos: O caso da Argentina. Banco Central del Uruguay. Montevideo, Uruguai. Disponível em: http://bcu.gub.uy/autoriza/peiees/jor/2002/iees03j060702.pdf. Acesso em: 11 out 2005 .

Bone, R. B. (2004). Ratings soberanos e corporativos: O rompimento do teto soberano pela Petrobrás e REPSOL-YPF. Instituto de Economia, Universidade Federal do Rio de Janeiro, Rio de Janeiro. Tese de Doutorado.

Bone, R. B. (2005). A importância dos fundamentos nos ratings soberanos brasileiros, 1994-2002. Anais do XXXIII Encontro Nacional de Economia, Dez. 2005, Natal.

Cantor, R. \& Packer, F. (1996). Determinants and impact of sovereign credit ratings. Economic Policy Review, 2(2). Disponível em: www.ny.frb.org/rmaghome/eco_pol/1096cant.html. Acesso em: 09 out 2007.

Canuto, O. \& Santos, P. F. D. (2003). Risco-soberano e prêmios de risco em economias emergentes. Ministério da Fazenda, Secretaria de Assuntos Internacionais. Temas de economia internacional.

Canuto, O., Santos, P. F. D., \& Porto, P. C. d. S. (2004). Macroeconomics and sovereign risk ratings. World Bank Discussion papers. Washington D. C.

Cruces, J. J. (2006). Statistical properties of sovereign credit ratings. Emerging Markets Review, 7(1):27-51.

Daniels, H. \& Kamp, B. (1999). Application of MLP networks to bond rating and house pricing. Neural Computing and Applications, 8:226-234.

Demuth, H. \& Beale, M. (1998). Neural Network Toolbox. For Use with MATLAB. Computation, Visualization, Programming. User's Guide, volume 3. The Math Works. Disponível em: http://www.mathworks.com/access/helpdesk/help/toolbox/nnet/. Acesso em: 20 jan 2008. 
Dutta, S. \& Shekhar, S. (1988). Bond rating: A non-conservative application of neural networks. Proceedings of IEEE International Conference on Neural Networks, 2:443-450.

Fausett, L. (1994). Fundamentals of Neural Networks. Prentice Hall, Englewood Cliffs, NJ. p. 309.

Ferri, G., Liu, L.-G., \& Stiglitz, J. E. (1999). The procyclical role of rating agencies: Evidence from the East Asian crisis. Economic Notes, 28(3):335-355.

Greene, W. H. (2002). Econometric Analysis. Prentice Hall, Upper Saddle River, New Jersey, 5 edition. 152 p.

Hangan, M. T. \& Menjah, M. B. (1994). Training feedforward network with the Marquardt algorithm. IEEE Trans. on Neural Networks, 5(6):989-993.

Haque, N. U., Mark, N., \& Mathieson, D. J. (1998). The relative importance of political and economic variable in creditworthiness ratings. IMF: Working paper 98/46.

Haykin, S. (2001). Redes Neurais: Princípios e Práticas. Bookman, São Paulo, 2 edition. 114 p.

Hooper, V., T., H., \& Kim, S.-J. (2008). Sovereign rating changes - do they provide new information for stock markets? Economic Systems, 32:142-166.

Kaastra, I. \& Boyd, M. (1996). Designing a neural network for forecasting financial and economic time series. Neurocomputing, 10(3):216-236.

Kim, J. W., Weistroffer, H. R., \& Redmond, R. T. (1993). Expert systems for bond rating: A comparative analysis of statistical, rule-based and neural network systems. Expert Systems, 10:167-188.

Kim, S.-J. \& Wu, E. (2008). Sovereign credit ratings, capital flows and financial sector development in emerging markets. Emerging Markets Review, 9:17-39.

Kreps, D. A. (1990). Course in Microeconomic Theory. Princeton University, EUA. 463 p.

Kröse, B. \& Smagt, P. V. D. (1996). An Introduction to Neural Networks. Universidade de Amsterdã, Amsterdã, 8 edition. 34 p.

Kumar, A., Rao, V. R., \& Soni, H. (1995). An empirical comparison of neural network and logistic regression models. Marketing Letters, 6(4).

Leichsenring, D. (2004). Endogeneidade e mecanismos de transmissão entre a taxa de juros doméstica e o risco soberano: Uma revisita aos determinantes do riscoBrasil. Faculdade de Economia, Administração e Contabilidade, Universidade de São Paulo, São Paulo. Dissertação de Mestrado. 
Maher, J. J. \& Sen, T. K. (1997). Predicting bond ratings using neural networks: A comparison with logistic regression. Intelligent Systems in Accounting, Finance and Management, 6:59-72.

Mas-Colell, A., Whinston, M. D., \& Green, J. R. (1995). Microeconomic Theory. Oxford University Press.

Minsky, M. \& Papert, S. (1969). Perceptrons: An Introduction to Computational Geometry. The MIT Press, London, England.

Moody's Investors Service (2003). Moody's rating symbols \& definitions. Disponível em: www.moodys.com. Acesso em: 19 set 2005.

Mora, N. (2006). Sovereign credit ratings: Guilty beyond reasonable doubt? Journal of Banking \& Finance, 30:2041-2062.

Novikoff, A. B. J. (1962). On convergence proofs of perceptrons. Anais do Symposium on Math Theory of Automata, Polytechnic Institute of Brooklyn. Brooklyn, NY: 615-622.

Obstfeld, M. \& Rogoff, K. (1996). Foundations of International Macroeconomics. The MIT Press, London, England. 349 p.

Partnoy, F. (2002). The paradox of credit ratings. University of San Diego Law \& Economy Research Paper n. 20.

Perrelli, R. \& Ramos, F. S. (1998). Cost predation in the Brazilian financial market: A game-theoretic approach. Anais do XII Convegno di Teoria dei Giochi ed Applicazioni, Genova - Itália.

Rasmusen, E. (2006). Games and Information. Blackwell, 4 edition.

Reinhart, C. M. (2001). Sovereign credit ratings before and after financial crises. University of Maryland and NBER. Working paper.

Riedmiller, M. \& Braun, H. (1993). A direct adaptive method for faster backpropagation learning: The RPROP algorithm. Anais do Proceedings of the IEEE International Conference on Neural Networks, San Francisco.

Rowland, P. (2004). Determinants of spread, credit ratings and creditworthiness for emerging market sovereign debt: A folow-up study using pooled data analysis. Republica de Colombia. Bogotá, Colômbia. Disponível em: http://www.banrep.gov.co/docum/ftp/borra296.pdf. Acesso em: 15 dez 2007.

Rumelhart, D., Hinton, G., \& Willians, R. (1986). Learning internal representations by error propagation. In Parallel Distributed Processing - Explorations in the Microstructure of Cognition. The MIT Press, London, England. 
Siu, K.-Y., Roychowdhury, V., \& Kailath, T. (1995). Toward massively parallel design of multipliers. Journal of parallel and distributed computing, 24(1):8693.

Standard \& Poor's (2001). Risco Soberano e Ratings Acima Do Soberano. Critérios - Comentários. Ratings de Crédito: Soberanias. Standard \& Poor's. Disponível em: www.santandarandpoors.com.br. Acesso em: 23 set 2007.

Standard \& Poor's (2002). Corporate Ratings. Criteria. Standard \& Poor's. Disponível em: www.standardandpoors.com. Acesso em: 13 set 2007.

Standard \& Poor's (2004). Critérios - Comentários: Ratings de Crédito Soberano: Principais Conceitos. Standard \& Poor's. Disponível em: www.standardandpoors.com. Acesso em: 20 fev 2008.

Stiglitz, J. \& Greenwald, B. (2004). Rumo a Um Novo Paradigma Em Economia Monetária. Francis, São Paulo.

The 2005 World Bank Development Indicators (2005). World bank. Disponível em: http://ddp-ext.worldbank.org/ext/DDPQQ/member.do?method= getMembers\&userid=1\&queryId=19. Acesso em: 30 out 2007 .

Veelenturf, L. P. J. (1995). Analysis and Applications of Artificial Neural Networks. Prentice Hall International, London, England. 